Will Economics Become an Experimental Science?

Author(s): Charles R. Plott

Source: Southern Economic Journal, Vol. 57, No. 4 (Apr., 1991), pp. 901-919

Published by: Southern Economic Association

Stable URL: http://www.jstor.org/stable/1060322

Accessed: 03/03/2014 18:43

Your use of the JSTOR archive indicates your acceptance of the Terms \& Conditions of Use, available at http://www.jstor.org/page/info/about/policies/terms.jsp

JSTOR is a not-for-profit service that helps scholars, researchers, and students discover, use, and build upon a wide range of content in a trusted digital archive. We use information technology and tools to increase productivity and facilitate new forms of scholarship. For more information about JSTOR, please contact support@jstor.org. 


\title{
Will Economics Become an Experimental Science?*
}

\author{
CHARLES R. PLOTT \\ California Institute of Technology \\ Pasadena, California
}

The expectations of the audience are rational because the answer I will give to the question posed by the title of this lecture is exactly what they expect. The answer is "yes." No doubt the expectations are also that I will not give a one-word lecture. A justification of such a radical answer is expected. Again, the expectations are rational. The natural way for me to explain my belief is to focus on the events that have facilitated and will continue to facilitate the broad application of laboratory experimental methods. Economics has been a non-laboratory science for several hundred years. Many have used economics as a classical example of a science in which laboratory methods are impossible. What has happened to make experimental methods applicable now and thereby change the way in which one can learn about economics? That question is the focus of this lecture.

The sheer growth of papers, researchers, and laboratories suggests that something has happened. From the early 1970s the number of papers has grown from two or three per year to numbers approximating 100 per year. The number of researchers has grown from a small handful in the early 1970s to hundreds. The number of locations of the research, and the number of laboratories have grown from one or two to the range of 30 or 40 . The growth is amazing but these are just trends. Such trends do not show the basic logic that is at work. The logic, the reasons for the activities, provides the proper support for the answer to the question posed in the title. The trends are simply manifestations of the logic and events.

\section{Six Seductive Steps to Sin and Intoxication}

I think that the foundations for the revolution that we can now see occurring began to be developed in the early 1970s. These foundations consist of six events. Collectively these events provide the bases for the self-sustaining growth and use of experimental methods in both the basic scientific and in the applied scientific aspects of economics. Now, to me basic science is fun; so much so that it must be sinful. Experimentation is also intoxicating and habituating in the sense that the more one does the more one wants to do. Consequently I will refer to the six events that form the foundation for the growth of modern experimental methods as the "Six Seductive Steps to Sin and Intoxication."

*Presidential Address delivered at the sixtieth annual meeting of the Southern Economic Association, New Orleans, November 20, 1990. The research support of the National Science Foundation and the California Institute of Technology Laboratory for Experimental Economics and Political Science is gratefully acknowledged. 


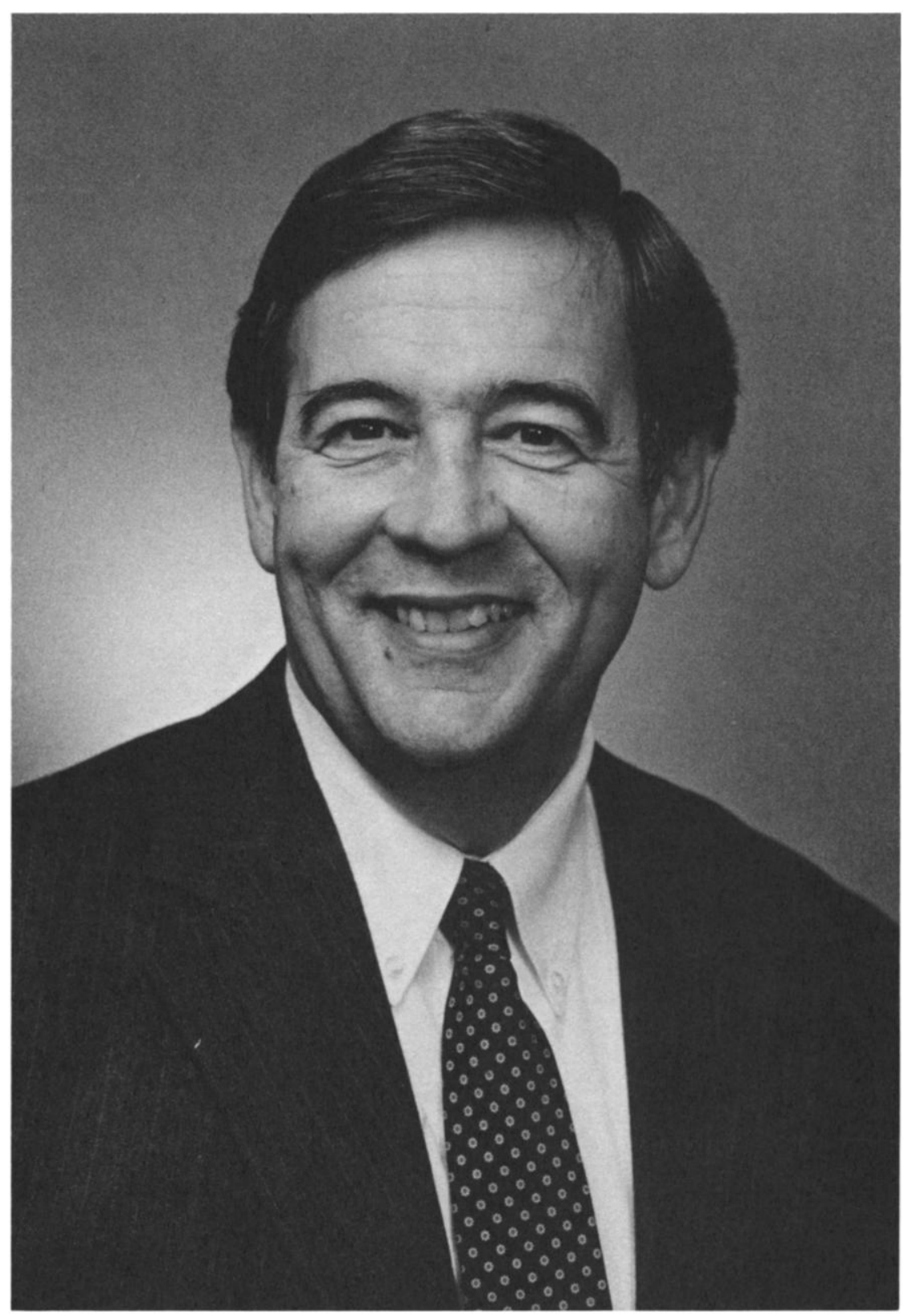

\section{Charles PAlost}




\section{Step 1: We Learned How to Pose a Question}

Prior to the early 1970s, the profession did not pose questions that could be answered by the application of experimental methodology. The questions primarily addressed aspects of economies as they are found growing wild in nature. Naturally occurring economies evolve in response to a wide variety of events and historical accidents. The possibility certainly exists that some of such events had nothing at all to do with any economic principles that might be at work. Economies found "in the wild," so to speak, are extremely complicated and the questions posed by the profession had to do with the properties of such creatures. Primarily the questions were about measurement and about the statistical properties of ongoing processes. (What is the elasticity of demand? What is the relationship between concentration and profits? What is the level of employment?) In order to learn about such statistical properties, the economy in question must be studied directly. The laboratory would seem to have nothing to contribute to such effort. The idea of performing replays of the historical evolution of an economy in order to get better observations does not make a lot of sense. Each observation would be very costly, to say the least.

Of course not all questions were about measurement. Many questions were about theory but even the theories tended to be directed to explanations about particular economies and particular situations in those economics. (What was the contribution of monetary policy to the great depression? What was the contribution of debt policies to the inflation of the 1960s? What were the causes of slums and ghettos in New York City? What were the contributions of technological change to the growth of the U.S. economy? What was the relationship between structure and performance in specific industries?) If the analysis is restricted to only questions of this sort, then only the data from these special economies, as they are found naturally evolving during a particular period of history, would seem to be relevant. Clearly, in many parts of economics a body of general theory had developed, but the focus of the profession was not so much on the general behavioral principles of the theory as it was on the application of theory to specific events. Again, in the absence of a capability to inexpensively replay history, a laboratory methodology would appear to have nothing to contribute.

Laboratory methodology involves a shift from a focus on particular economies as they are found in the wild to a focus on general theories, models and principles that govern the behavior of economies. This distinction between the study of an economy and the study of models, theories and principles of economics is subtle so an elaboration might prove useful. The logic is as follows. General theories must apply to simple special cases. The laboratory technology can be used to create simple (but real) economies. These simple economies can then be used to test and evaluate the predictive capability of the general theories when they are applied to the special cases. In this way, a joining of the general theories with data is accomplished.

Before continuing further, an example of a simple, laboratory economy consisting of one market will be given. People are assembled. Some of the people are designated as "buyers" and some are designated "sellers." Buyers are involved with the experimenter through a contract of the following sort. Buyer $i$ is assigned a "redemption value" function, $R^{i}\left(X_{i}\right)$ which indicates the amount of (real) dollars he or she will receive from the experimenter as a function of $X_{i}$, the quantity of the commodity purchased by $i$. The buyer $i$ keeps as profits the difference between $R^{i}\left(X_{i}\right)$ and whatever he or she paid to sellers for the units. Similarly, the experimenter's contract with seller $j$ is that $j$ will pay the experimenter an amount of dollars $C^{j}\left(X_{j}\right)$ depending on the quantity, $X_{j}$, sold by $j$. Seller $j$ keeps as (real dollar) profits the difference between the revenue he or she received from buyers and the cost paid to the experimenter. 
If the competitive model is applied to the market, then each buyer can be represented by a demand function that satisfies the equation $\left(\partial R^{i}\left(X_{i}\right)\right) / \partial X_{i}-P=0$. Each seller can be represented by a supply function that satisfies the equation $P-\partial c^{j}\left(X_{j}\right) / \partial X_{j}=0$. That is, the individual quantity demanded is determined by an equating of price to marginal benefits and the individual quantity supplied is determined by an equating of price to marginal cost. The market demand is derived by a sum of individual demand functions and the market supply is determined by the sum of individual supply functions. The competitive model then predicts that the price will be the one that equates market demand with market supply. Clearly the law of supply and demand is applied very generally and to economies much more complicated than the one just described. It is only natural to expect that if the law works in very complicated cases then one should expect it to work in the simple case as well. If it does not then a substantial reassessment of the theory would be in order. The conclusion of many laboratory experiments is that it does indeed work in the simple cases.

Figure 1-A displays the market demand and supply from a simple laboratory market conducted at Caltech. Figure 1-B shows the time series of trades that took place in the market. The market was organized by a computerized multiple unit double auction. The dots represent contract prices displayed in the order in which contracts occurred. The vertical lines are the end of market periods or "trading days." Each trading day was a replication of the previous day in the sense that the market demand and supply was the same. As can be seen, the time series approaches the prediction of the competitive model. Contract prices approach the competitive equilibrium price and volume approaches the competitive equilibrium volume as the trading periods are replicated.

The demand and supply diagram is useful but it does not reflect the potential variety of laboratory applications that is possible. Almost all economic theories and models have the same form which elsewhere [17] I have called the "fundamental equation" represented in Figure 2. Almost all economic theories and models rest on concepts of preferences, technology, (or feasible sets), and institutions. These concepts form the basic parameters which are supposed to dictate the behavior of the economy. The fundamental equation captures the essence of the relationships. Fix the preferences, the feasible set, and the institution (perhaps along with beliefs) and the models will yield a prediction. It is important to note that it makes no difference where the economy is found. The economy could have been found evolving in nature or it could have been a home-grown, laboratory variety; as long as the parameters are known, the theory will produce a prediction. It is this general property of theory that is important for laboratory experimental work. Figure 2 will help make the point more clearly.

Theories and models can take many competing forms or be based on different principles of behavior and still have the properties of the fundamental equation. Those captured by the box in Figure 2 are examples. Given some fixed "economic environment" of preferences, institution, and feasible sets, the outcomes predicted could be based on any of a number of different cooperative game theoretic models or the prediction could be based on any of a large number of noncooperative models. Consider first the cooperative model options. Cooperative game models can differ according to the choice of dominance relations and can differ depending upon the nature of the characteristic function. Differences in models can also reflect different selections from the set of solution concepts (core, bargaining sets, etc.). Even within the class of cooperative game models the number of models that could be applied to the same environment is large. However, cooperative models do not exhaust the possibilities. The model applied to the same environment might be based on noncooperative theoretic principles. Noncooperative theories can differ according to hypotheses about the information structure generated by the institutional arrangement. 

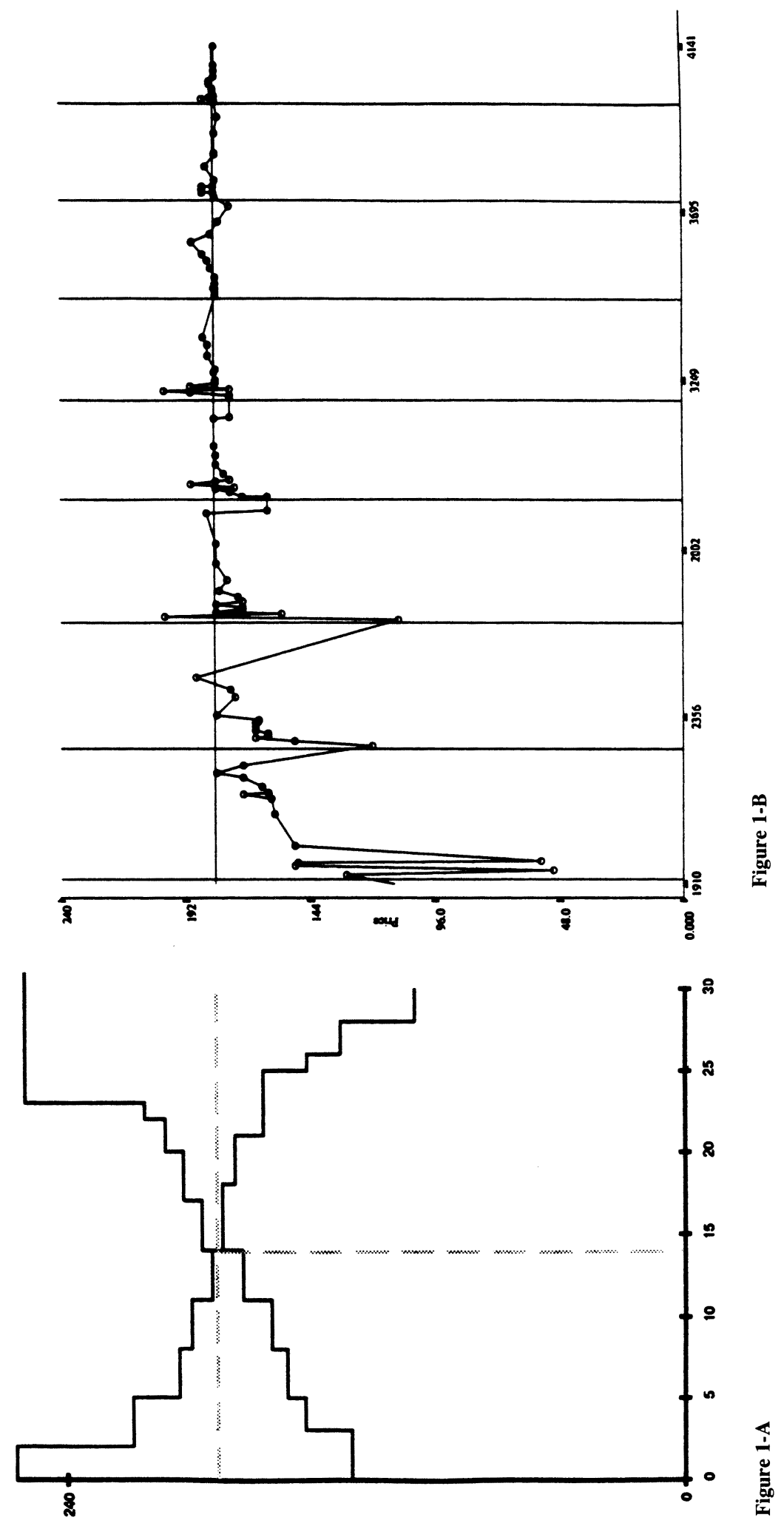


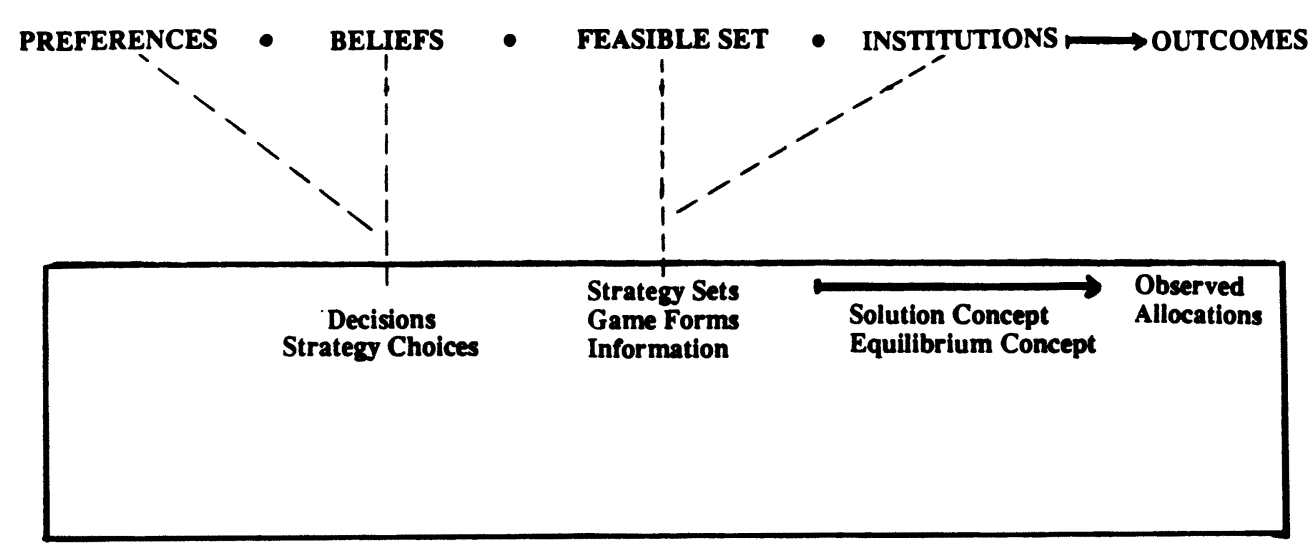

TYPICAL MODEL

Figure 2. Fundamental Equation

The number of possible models is also expanded by the choice of an equilibrium concept (Nash, perfect Nash, etc.). Cooperative games and non-cooperative games do not exhaust the possibilities. The model might be based on principles of nonstrategic behavior and yield outcomes like those predicted by the competitive model. The number of potential models is impressive.

The lessons of Figure 2 are firstly, that models of economies found in the wild tend to have a similar structure and that structure is captured by the fundamental equation. Secondly, such models are general models involving basic principles intended to have applicability independent of time and location except to the extent to which time and location have an effect on the variables of the fundamental equation, (preferences, institutions, information, and feasible sets). Third, we see that a staggeringly large number of theories exist. One purpose of the laboratory is to reduce the number by determining which do not work in the simple cases. The purpose is also to improve the models by exploring how a model might be changed to make it work better in the simple cases. General models, such as those applied to the very complicated economies found in the wild, must apply to simple special cases. Models that do not apply to the simple special cases are not general and thus cannot be viewed as such. The trick is to notice that economies created in the laboratories might be very simple relative to those found in nature, but they are just as real. Real people motivated by real money make real decisions, real mistakes and suffer real frustrations and delights because of their real talents and real limitations. Simplicity should not be confused with reality. Since the laboratory economies are real, the general principles and models that exist in the literature should be expected to apply with the same force to these laboratory economies as to those economies found in the field. The laboratories are simple but the simplicity is an advantage because it allows the reasons for a model's failure to be isolated and sometimes even measured.

The process of learning is roundabout. The questions posed by experimentalists address the points of accuracy and the points of failure of general models and principles of economic behavior. Theories that predict relatively poorly in the laboratory are either rejected or refined. Models and principles that survive the laboratory can then be used to address questions about the field. Why something happened or what might happen in some naturally occurring economy are questions addressed by models that have been refined by laboratory testing. It is the understanding of the nature of those models, some of their points of accuracy and failures, that can be gleaned from laboratory studies. Presumably this understanding helps with field applications. The labora- 
tory is not a source of direct simulation of what might happen in the field. The use of theory is an intervening stage. The learning process is roundabout.

A recognition of this roundabout means of learning removed two intellectual constraints which together had made laboratory methods useless. The first was a belief that the only relevant economies to study are those in the wild. This belief suggested that the only effective way to create an experiment would be to mirror in every detail, to simulate, so to speak, some ongoing natural process. Early experimenters were guilty of yielding to this belief and described experiments as simulations of a market [21] or attempted to include in their experiments much of the rich and complicating detail found in many markets [9]. As a result the experiments tended to be dismissed either because as simulations the experiments were incomplete or because as experiments they were so complicated that tests of models were unconvincing. In other words, the experiment would be dismissed either because it did not mirror some natural process, or because it did. Once models, as opposed to economies, became the focus of research the simplicity of an experiment and perhaps even the absence of features of more complicated economies became an asset. The experiment should be judged by the lessons it teaches about theory and not by its similarity with what nature might happened to have created.

The second constraint to the development of laboratory experiments was a belief about the proper way to test a theory. Typically a theory is viewed as being of the form "if $x$ then $y$." Following this belief, the proper way to test a theory is to create a circumstance in which all of the assumptions of the theory are satisfied, the $x$ part of the statement, and then conduct the experiment to see if $y$ is the result. If $y$ is not observed then the theory is rejected as being false. The problem with this methodology is not that it is wrong. The problem is that the assumptions of economic theories are seldom stated in operational terms and the theories themselves can be so vague that tests in the sense above are practically impossible. For example, a proposition frequently stated as an "assumption" of the competitive model is that each agent "believes" that his/her actions will have no effect on price. If the theory is stated in that form, then for practical purposes laboratory testing is impossible. In order to test the theory in that form, the experimenter must somehow know what exists in the minds of subjects. Since such data can never be known to the experimenter, the theory cannot be tested in the laboratory, in the field, or in any other way. The "if" part of the conditional cannot be known to be satisfied.

Experimenters learned to sidestep this issue by posing tests as contests among competing models. The question posed by the experimenter evolved from a single question of the form "is this theory true?" to include questions like "which of these models best predicts what is observed in the simple experimental economies?"; or, to include a slight variant of that question "what are the circumstances under which the predictions of this theory/model improve or deteriorate?".' This new, broader set of questions is based upon the recognition that simple, special cases of economies are legitimate entities to study and that the predictive capacity of a theory or model might be unrelated to whether or not the assumptions are satisfied. ${ }^{2}$ By considering a broader set of questions than historically had been considered, experimentalists began to develop the art of posing questions that a laboratory experiment can answer. Plott [4].

1. A clear early statement of this change in perspective to deal with many competing models is in Fiorina and

2. See Goodfellow and Plott [10] for a discussion of this issue. When a sharp differentiation between assumptions and principles is absent in the theory, the classical concept of testing a theory does not work. 


\section{Step 2: Some Important Discoveries Were Made}

During the very early years of experimentation, three very important discoveries were made. In some sense these establish a foundation for all subsequent work but they were not appreciated at the time. In fact, it is only recently, after many replications, and hundreds of experiments of different types, can we look back and recognize these early events as discoveries.

Chamberlin [1] made major progress toward studying the law of supply and demand, although he really failed to recognize the nature and the importance of his discovery. Hoggatt [11], Sauermann and Selton [19, 20], Fouraker and Siegel [7] all discovered the power of the Nash equilibrium and Fouraker and Siegal were the first to use laboratory methods to study the influence of institutions. Vernon Smith [21] discovered the operation of the law of supply and demand in open outcry markets. Figure 1 is simply one sort of replication of what Smith discovered. The decade following these early discoveries contains several important experiments but I think two discoveries in the early 1970s, both contained in the same paper [18], provide one of the keys to unlocking the door to understanding what happened at Step 2.

The first discovery was that a concept of efficiency can be applied to evaluate and measure the performance of an experimental market. The discovery was simply that a cost/benefit analysis could be applied directly to experimental markets. The area under the demand curve is the amount paid to subjects by the experimenter. The area under the marginal cost curve is what subjects pay to the experimenter. The consumers' surplus plus the producers' surplus is maximum total earnings that subjects can get from participation. The gains from trade in the laboratory market are the subject payment cost of the experiment to the experimenter. If all gains from trade are exhausted, then as a group, subjects have earned the maximum total possible from the experiment. The efficiency with which the market facilitates the acquiring of such gain would be $100 \%$ in case the maximum is attained. The efficiency of market operations can then be measured by the actual payments to subjects divided by the maximum possible. In multiple market experiments with production, dollar payments may need to be replaced by other measures found in the welfare economics literature.

This simple technique has very important applications. It can be used to measure the efficiency with which different institutions can operate to solve the same problem. Within a fixed economic environment (preferences and feasible sets), the experimenter can conduct different experiments with different institutions and compare the efficiencies. Thus, the technique provides a way to compare and evaluate the performance of different institutional arrangements. It is especially important to notice that this comparative analysis can take place even though the experimenter may have no reasonable theory of why the institutions affect the markets as they do. Experiments can be useful even in the absence of theory. Experimentalists could proceed in meaningful directions even in cases in which the theory was not worked out at all.

The second discovery was actually a rediscovery that institutions have an effect on market performance. This time, however, the institution and the effect were both clearly identified and the institution was not just any old institution. The institution was posted prices, similar to the rate posing process that have been used by the Department of Transportation and the Interstate Commerce Commission for years. Furthermore, the effect was not just any old effect. Posted prices cause prices to go up and efficiency to go down relative to what would be the case under an open-outcry system. Exactly why this occurs is still an open question although the best model developed so far is the mixed strategy solutions of a Bertrand game representation of the market.

These two discoveries set the stage for the use of laboratory experimental methods in policy 
analysis. The efficiency measure and related concepts can be used to measure and identify the difference between competing modes of market organization. This comparison can proceed even if no good theoretical representation of processes exists. That is, the empirical work can proceed in the absence of theory although the presence of theory certainly enhances its usefulness. Furthermore, since the posted price was an important variant of market regulatory machinery, the analysis could be focused directly on regulatory issues. Evaluation of the relative performance of market organizations in the laboratory provided a new source of insights about how such institutions might operate when implemented in the field. Laboratory-based policy analysis was made possible [12].

\section{Step 3: Economic Theory Advanced}

The stunning changes in theory that took place in the late 1970s and 1980s do not need to be reviewed here. Information became a key variable and, with this variable, scientific interest in noncooperative game theory which, for practical purposes, was a dead subject prior to the late 1970 s, began to be stimulated.

The newly developed tools of analysis suggested the existence of very subtle relationships among the actions taken by economic agents and the institutions in which they are operating. The implications of rationality of self and of others began to grow in importance. Efficiency began to expand from simple allocation efficiency to information efficiency and both began to depend critically upon the ability of agents to assimilate information from complex data and the knowledge that others could do the same. Slight changes in institutional form could have dramatic implications in terms of the predictions of the new game theoretic models. Critical features of models used in applications began to be so delicate that any testing in the field would be essentially hopeless. History does not often shape itself to suit the convenience of analysts who might like to test some of the very basic propositions about human actions and market behaviors that modern economic theory suggests might exist.

The matrix game represented in Figure 3 will provide some intuition about the issues for those who are not versed in game theory. In that game the outcome in the lower right hand corner is a Nash equilibrium. If row player chooses B and column player chooses $\mathrm{C}$, neither has an incentive to change given the choice of the other. How might the system get there? Row player can see that column player will not choose B because for column player, B is dominated by both columns $\mathrm{A}$ and $\mathrm{C}$. Furthermore, row player understands that column player understands that if column B is not played, then for row player row A is dominated by row B. So, row player is not likely to play A. It follows that column will play C. By such repeated arguments that apply not only rationality of self but also rationality of others, and so forth, a presumption exists that the lower right hand corner will be the outcome.

This role of rationality and public knowledge of rationality is an important feature of models and we will return to this feature of theory later. For now, it is sufficient to note that the choice of concepts of equilibrium used in a model can have an impact on predictions about the ultimate consequences of institutions on allocations. The example is really only illustrative of the issue. Modern theory has produced dozens of interesting new concepts of equilibrium and/or solution concepts, especially in cases in which the economic situation involves asymmetric information. Such theory also suggests the existence of what otherwise might be thought of as strange phenomena such as rational expectations equilibria. 


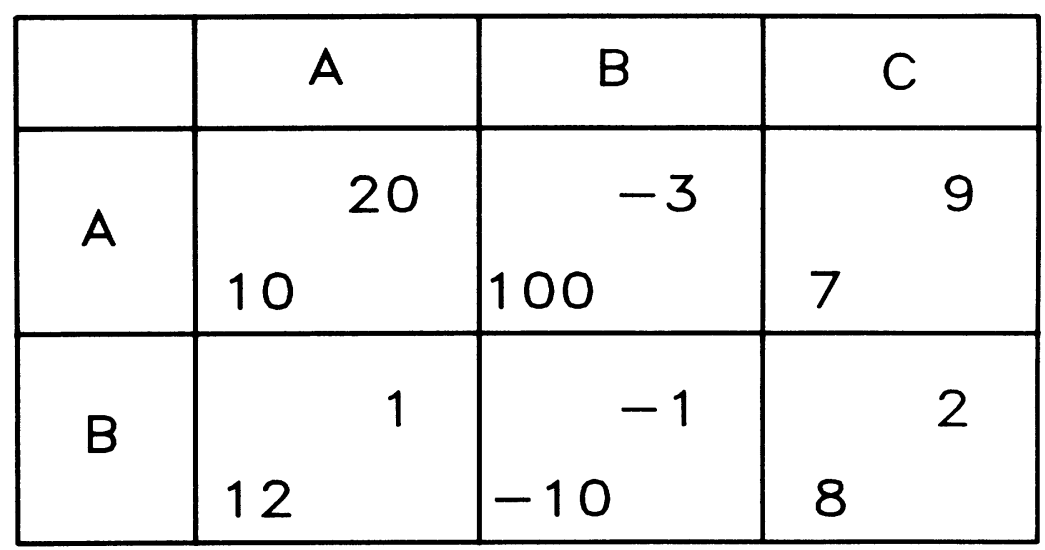

Figure 3. Matrix Game with Row Player and Column Player

Even though the solution concepts might have dramatically different consequences for institutional behavior, the data needed to distinguish between them, to determine which of them is the most accurate, can only be revealed at certain critical points of the decision making process. If the data can only come from the field, and from repeated observations of special circumstances found there, then the appropriate tests will probably never be conducted. The only practical source of data that can be obtained within an appropriate time frame and serve as a guide for many of the newly developed theories is the laboratory.

\section{Step 4: Laboratory Data Suggests that Theory Is on the Right Track}

It is one thing to say that the laboratory can be used as a source of data. It is very much another thing to say that something exists by way of theory that is worth the effort needed for a test. Experiments conducted in the late 1970s provided strong suggestions that modern theories were not completely hopeless and, indeed, appeared to be on the right track.

Many examples exist. The law of supply and demand was well established by the late 1970s. The importance of the CORE of game representation of committee processes had also been well established by the late 1970s. Rational expectations had received strong support. In addition, the work with nonhuman animals in the early 1970 s was extremely important because it leads directly to the hypothesis that a biological bases exists for the preference and optimization behavior that is so fundamental to modern theory.

Perhaps the easiest examples to explain are the experiments with sealed bid auctions. The theory of auctions is one of the most completely developed theories in the social and economic sciences. The theory is well developed in the sense that the basic principles of game theory can be applied to create a model for which many of the definitions and assumptions can be made operational and implemented in an experimental environment.

Consider an economic environment in which one unit of a good is sold by a sealed bid auction process. The values of each of $n$ bidders are drawn independently from a probability density function $f(v)$. Having knowledge of his or her own value $v$ and the knowledge that the value of others are drawn from the same p.d.f., the individual must tender a sealed bid. The item is then sold to the highest bidder at his/her bid. 


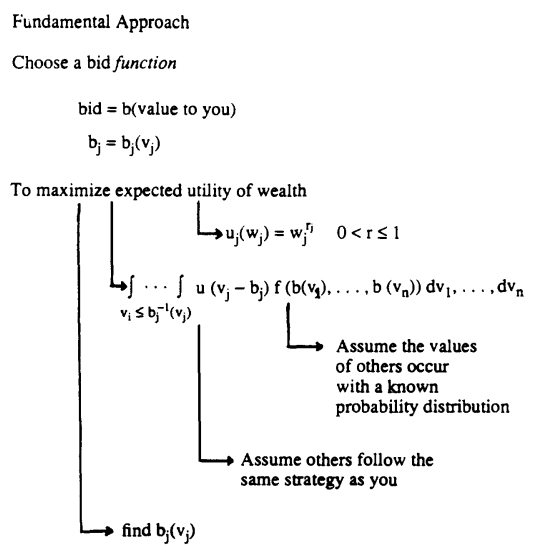

Figure 4. Sealed Bid Auction: Problem of Individual Choice

The value of the object to each individual will, in general, be different. From the point of view of any single individual, the values of the other people are random with some known probability structure. Of course, the individual would like to purchase the object and obtain it at a low price. Specifically, if $w$ is the wealth of the individual, and $v$ is the value of the item to that individual, then the individual's utility given a winning bid at bid price $b$ is $u(w+v-b)$. The utility of the auction outcome if the individual fails to tender the winning bid is simply $u(w)$.

The problem faced by the individual who knows his/her own value $v$ is to choose a bid. Since the bid depends upon the individual's value $v$, the implicit decision is the choice of a bid function $b=b(v)$ indicating what the individual would do depending upon the circumstances. The individual knows that other individuals face the same task and will develop their own individual bid functions.

The situation lends itself naturally to a game theoretic model. The theory is remarkably complex if $f(v)$ is not uniform and if individuals are not risk neutral. From an individual's point of view, the problem is outlined in Figure 4. Each individual must choose a bid function, a "strategy" in game theoretic terms, from all of the bid functions that might be imagined (the "strategy set"). Each individual's payoff depends upon his/her own choice of strategy and the strategy choices of others. Under suitable conditions on the probability distribution that describes the distribution of values across agents and under suitable conditions on the individual attitudes toward risk, a Nash equilibrium of the implied game exists. These equilibrium bid functions can be computed and compared to the actual bid functions of people participating in auction experiments.

Figure 5 displays three actual decisions of an individual in an auction experiment. Three people were competing. ${ }^{3}$ In this environment the values are drawn from 0 to $\$ 10$. The probability that an individual's value is between 0 and $\$ 5$ is .8 and the probability that the value is $\$ 5$ or more is .2. Values within a range are equally likely. The first of the three draws by the individual was $\$ 2.45$ and the resulting bid was $\$ 2.20$ as shown on the figure. This was a winning bid so the profit of this individual was $\$ .25$. The bids of the other two subjects were $\$ 1.24$ and $\$ .30$. Of course, the amounts of money were real and the individual kept all profits. On the second draw the individual received a value of $\$ 1.11$ the bid was $\$ 1.00$. The bids of the other two were

3. Space prevents a detailed description of the experimental procedures and environments. For a detailed discussion of procedures see Cox, Roberson and Smith [2]. These data for the use of nonuniform distribution over values are part of a research project of Kay-Yut Chen and Charles Plott. 


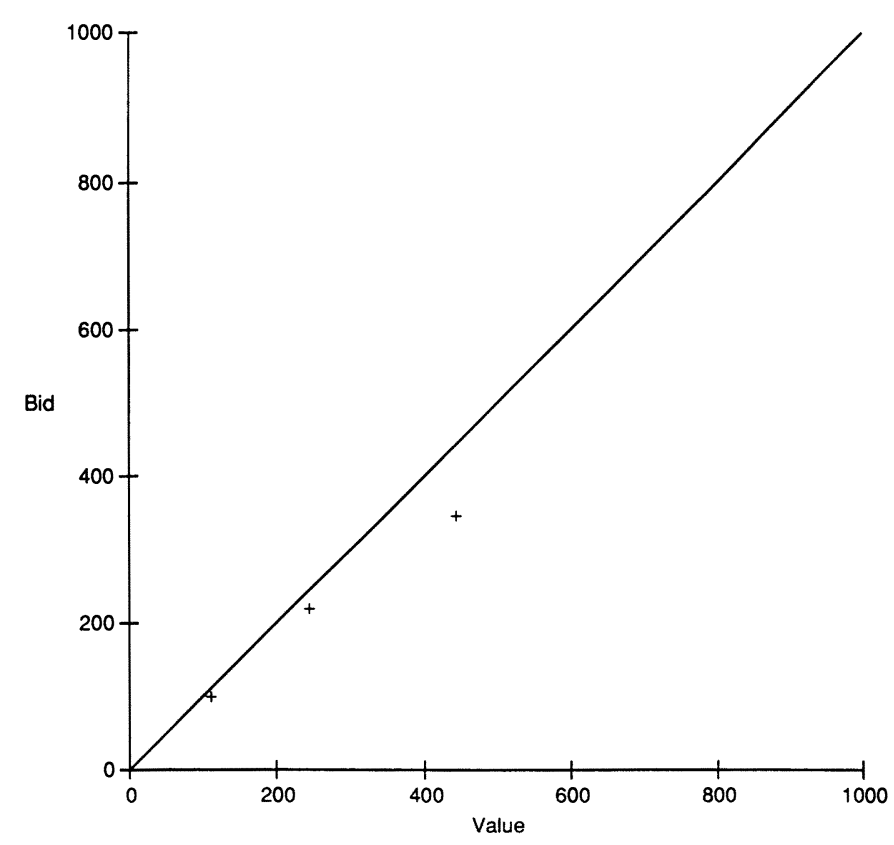

Figure 5. Drawn Values and Bid Choices

$\$ 4.01$ and $\$ 3.06$ so the profit of this individual was zero. When the value drawn was $\$ 4.44$ the individual bid was $\$ 3.47$. As can be seen, the elements of a bidding function $b(v)$ are beginning to appear in the figure. The question is whether or not the function is one predicted by theory.

Figure 6 contains all of the bids made by this individual. It also contains two different solutions to the game theoretic representation of the auction process. The lowest, most inaccurate bid function is based upon the assumption that this individual and others are risk neutral. As can be seen, the model predicts areas in which nonlinearites might occur but the risk neutral model is certainly inaccurate quantitatively. The bids it predicts are much lower than actual bids.

The second bid function is based upon the assumption that bidders are risk averse (constant relative risk aversion) with a random risk aversion parameter. ${ }^{4}$ The simple risk aversion parameter is estimated from the linear portion of the bid function. As is obvious from the figure, the model begins to take the shape of the data. The accuracy of the model when applied to other individuals' data is similar to the one in the figure.

The point of this example is not that game theory has established some sort of iron law of behavior. The point is much more modest. The data from auction experiments, market experiments, committee experiments, etc. all have a common thread. Principles of economics and game theory lead to models that capture much of the essence of behavior. The data strongly suggest the existence of uniformities of behavior in complicated, competitive environments and that theory is on the right track. The data suggest that modern theorizing has been worth the effort. Theory appears to provide windows through which fundamental uniformities of human behavior can be viewed. Even though experimental work suggests that more theory is needed, the message that began to emerge from research in the late 1970 s had clear and substantial positive elements. That positive message is an example of Step 4.

4. See Cox, Smith and Walker [3] for the details of such a model. The solutions for the nonuniform distribution case are taken from the Chen and Plott project. 


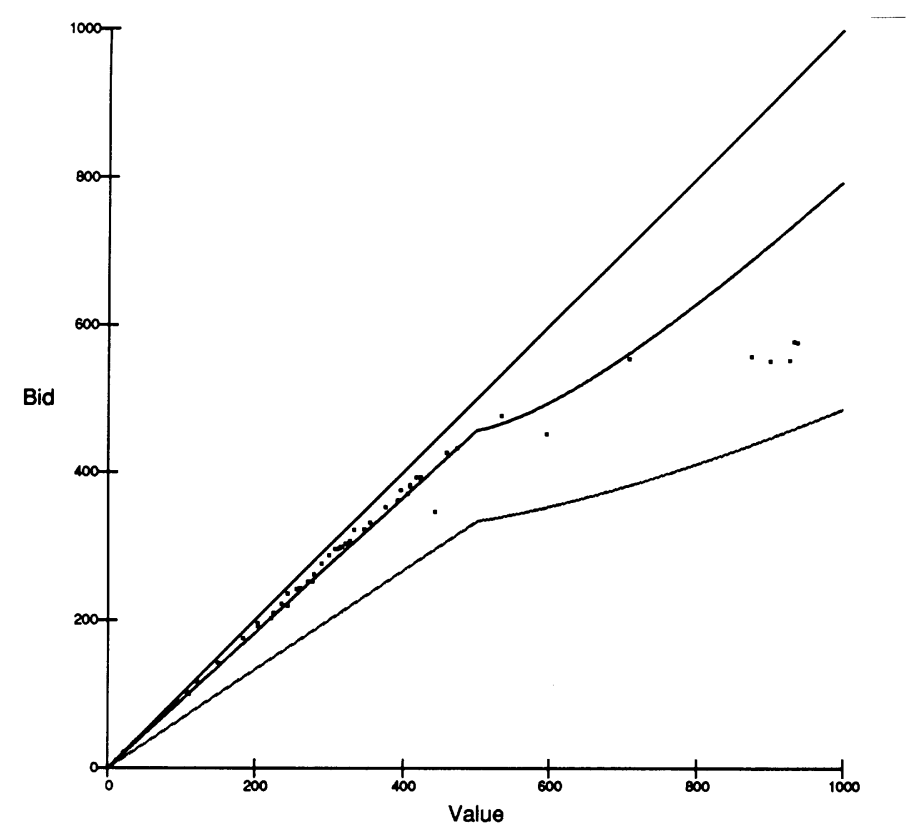

Figure 6. Observe Bid Function and Theoretical Bid Function for One Individual

\section{Step 5: Paradoxes Begin to Appear}

When theory appears to be going in the right direction, the natural reaction of the scientist is to explore in those directions as far as possible. Some of the more important directions suggested by modern theory are those provided by principles of game theory. The questions posed by those who explore in such directions are whether or not the theory continues to be accurate when some of its more subtle implications are tested. A second and independent set of research directions is suggested by the procedures and institutions previously explored experimentally. The question posed is whether or not the stylized facts that emerged from the study of very simple environments continue to be observed as the institutions change and take on increasingly complex properties. Such experiments are checks on the robustness of previous results. Failures to obtain positive results in either direction are called "paradoxes" (as opposed to "rejected theories").

Paradoxes began to appear in many contexts. Three of the most fascinating will be considered here. They are, in turn, the winner's curse, the behavior in centipede experiments, and the existence of bubbles in asset markets. These three are interesting because the theory that served well to explain behavior in closely related experiments predicts that the phenomena observed in these experiments cannot exist as a matter of principle. The very existence of the phenomena suggests the need for a reworking of theory at a very fundamental level.

Experiments in which the winner's curse is observed involve only a seemingly, slight alteration in the procedures of the first price auction experiments discussed in the section above. The structure is changed from a private value auction to a common value auction in which the value of the object sold is the same for all bidders. The value of the object is randomly determined. Each agent is then given a clue to the true value. The clue is drawn independently from a probability distribution that depends upon the true value. The agent must then determine a bid based upon the clue. 

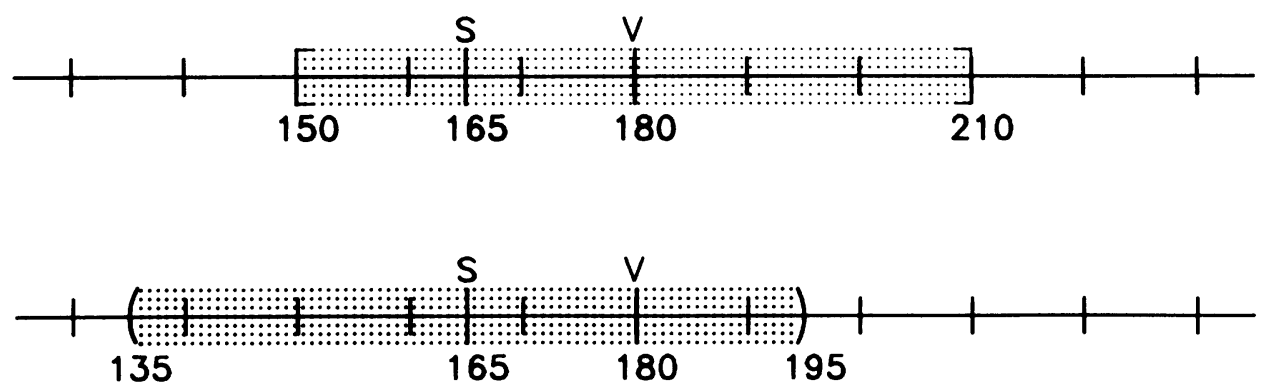

Figure 7. Common Value Auction: Value and Signal Relationship

\begin{tabular}{|c|c|c|c|c|}
\hline $\begin{array}{c}\text { Our } \\
\text { Sample }\end{array}$ & $\begin{array}{c}\text { Range of } \\
\text { Possible Values } \\
\end{array}$ & Our Bid & $\underset{\text { Bid }}{\text { Winning }}$ & $\begin{array}{l}\text { Actua } \\
\text { Value }\end{array}$ \\
\hline 100 & {$[70,130]$} & 90 & 100 & 85 \\
\hline 136 & {$[106,166]$} & 126 & 160 & 160 \\
\hline 158 & {$[128,188]$} & 148 & 175 & 173 \\
\hline 182 & {$[152,212]$} & 162 & 162 & 156 \\
\hline
\end{tabular}

Figure 8. Common Value Auction: Example of Information and Bids

The winner's curse phenomena, first observed experimentally by Kagel and Levine [13] is that the winning bid is almost always above the true value of the item. That is, the auction winner almost always loses money. The existence of the phenomena creates a paradox because models constructed from the basic principles of game theory predict that the phenomena cannot exist.

Figure 7 can help with an explanation of the experimental environment. In this experiment, the value of the item $v$ was drawn uniformly from 0 to $\$ 500$. Seven bidders tendered bids. The clue for each agent was drawn uniformly from $v \pm \$ 30$ where $v$ was the actual value of the item. If the winning bid was above $v$, then the winner lost money. If $s_{i}$ is the clue received by individual $i$, the optimal bidding rule for risk neutral agents is $b\left(s_{i}\right)=s_{i}-\$ 30$. In the example in the Figure, $v$ is 180 and $s=165$. The individual sees only 165 and knows that $v \in[135,195]$.

Figure 8 contains some of the actual data from the point of view of one agent in an experiment conducted by Lind and Plott [15]. The Lind and Plott experiment, conducted in the spirit of distrust, was a replication of the Kagel and Levine experiment. The signal seen by the individual is called "our sample." The bid tendered by the individual is called "our bid." As can be seen, this individual never followed the optimal bidding rule. The bids of this agent and the bids of others were always too high. The table shows that this agent saw losses occurring repeatedly to other agents in auction after auction and in period 4 experienced a loss himself.

The overbidding that contributes to the winner's curse phenomena is exhibited by almost all agents. It continues over repeated trials. When agents who exhibit Nash-type behavior in private value auctions are placed in common value auctions, the winner's curse immediately appears. 
Table I. Decisions in Centipede Game

\begin{tabular}{lrrrrrrr}
\hline \$ Amounts of Money & .40 & .80 & 1.60 & 3.20 & 6.40 & 12.80 & 25.60 \\
& .10 & .20 & .40 & .80 & 1.60 & 3.20 & 6.40 \\
\hline Choosing Individual & 1 & 2 & 1 & 2 & 1 & 2 & 1 \\
\hline Trials 1-5 & & & & & & & \\
$\quad$ \# of People Choosing & 145 & 145 & 137 & 112 & 64 & 16 & 4 \\
$\quad$ Number of Terminations & 0 & 8 & 25 & 48 & 48 & 12 & \\
$\quad$ Probability of Termination & 0 & .06 & .18 & .43 & .75 & .81 & \\
Trials 6-10 & & & & & & & \\
$\quad$ \# of People Choosing & 136 & 134 & 124 & 93 & 33 & 10 & \\
$\quad$ \# of Terminations & 2 & 10 & 31 & 60 & 23 & 9 & .90 \\
$\quad$ Probability of Termination & .01 & .07 & .25 & .65 & .70 & \\
\hline
\end{tabular}

Source: Richard D. McKelvey and Thomas Palfrey [16]

How can individuals who otherwise appear so rational produce such "non-rational" behavior? That is the paradox. The resolution posed by Kagel and Levine was that individuals failed to properly compute an order statistic. If all individuals are rational, then bids increase with the value of the clue. This means that the individual with the largest clue (which will almost certainly be above the value of the item) will win the auction. The bid must then be properly discounted from the clue to reflect the fact that if the bid wins, then the clue was the most extreme above the value of the object. The proposed resolution of the paradox is that individuals may be rational but they fail to anticipate and incorporate the rationality of others into their decisions. They fail to realize that they will win the auction only when they have the highest signal and/or they fail to discount by the appropriate order statistic.

The second example is called the centipede game. In this process, two individuals participate in a finite sequence of moves that involve options of the following sort. The first person has an option of two amounts of money $\{x, y\}$ with the property that $x>2 y$. If the chooser takes one of the amounts of money, the process ends with the choosing agent keeping the amount taken and the other agent receiving the other amount. If the first agent passes, then both amounts of money are doubled and the second player has the choice between $\{2 x, 2 y\}$ or passing back to player one and allowing both amounts to double. If players continue to pass, then at the $k$ th decision the amounts will be $\left\{2^{k} x, 2^{k} y\right\}$. The process is known (publicly) to terminate at decision $T$ at which point the choosing agent must choose the higher of $\left\{2^{T} x, 2^{T} y\right\}$ and does not have an option to pass.

A natural game theoretic representation of the process is a game with perfect information. The Nash equilibrium of such a game is for the first chooser to take the largest amount and terminate the game immediately. This result follows by backward induction from the terminal period, the perfect information, and the "rationality" of both players. The $T-1$ player should recognize that he or she will get the smaller amount if "pass" is chosen and, therefore, would choose to take the larger amount at $T-1$ and stop the game. However, the $T-2$ player anticipates that and so would terminate at $T-2$. The logic works its way back to $t=0$. Interest in the game stems directly from the lack of intuitive appeal of the (only) Nash equilibrium.

Experiments with the centipede game conducted by McKelvey and Palfrey [16] started with the amounts $\{\$ .40, \$ .10\}$ and continued for a maximum of seven decisions ending with a maximum of $\{\$ 25.60, \$ 6.40\}$. Contrary to the perfect information game theoretic model, agents do 
not take the cash and terminate the game on the first move. However, as agents have more experience, the terminations occur earlier. The table contains the relevant statistics from the McKelvey and Palfrey study. The data are partitioned into two sets according to subject experience with the game. Each subject participated in 10 trials (each trial could involve up to seven decisions). At the first trial subjects had no previous experience. At the 10th trial subjects had played the game 9 previous times with 9 different people. In the table the results of trials $1-5$ are presented separately from trials $6-10$.

First notice that the probability of termination at stage 1 is not $100 \%$ as predicted by theory. In trials 1-5 no game terminated at the first choice. In trials 6-10 only 2 of 136 people, or $1 \%$, chose to terminate at the first move as theory predicts. However, as can be seen, the probability of having terminated by a given stage in trials $1-6$ stochastically dominates the probability of having terminated in that same stage in trials 1-5. Even the rate of termination is higher at all stages except the 5th stage.

Such data present an obvious puzzle. Are principles at work which cause behavior to converge with experience toward Nash play? The Nash play captures some of the behavior in the sense that terminations occur substantially prior to the final round. But certainly the Nash equilibrium model does not exactly describe everything that happens. How can the model be modified to account for what is observed? As can be seen, the puzzles and paradoxes begin to emerge as both theory and experiments become more sophisticated.

The final example is the behavior of asset markets. Early experiments with asset markets by Forsythe, Palfrey and Plott [5; 6] gave clear support for rational expectations. The assets studied had two-period lives and the dividends involved no random component. The environment was complicated by Friedman, Harrison and Salman [8] to include a three-period life and random dividends. The results did not differ substantially from those of Forsythe, Palfrey and Plott. Motivated by these early results, Smith, Suchanek and Williams [22] decided to explore assets with long lives and random dividends. Experimentation under generalizations of existing procedures and environments is a natural thing to do.

The asset studied by Smith, Suchanek and Williams had a fifteen-period life. Each period it paid a dividend which was drawn with equal probabilities from the set $\{\$ .60, \$ .28, \$ .08,0\}$. Thus the expected dividend each period was $\$ .24$. At period 1 the expected dividend stream was $\$ .24 \times 15=\$ 3.60$ and in period 2 the expected value is $\$ .24$ less. The middle curve in Figure 9 shows the "fundamental value" of the asset. If the asset paid the maximum possible dividend (\$.60) throughout life (a very unlikely event), then the value would be the top curve in the figure.

The dots in the figure are contracts executed through a computerized market. As can be seen, the assets began trading at prices slightly below the expected value and in period 2 prices are near the expected value. However, by period 3 the assets were trading above expected value. Prices increased slowly from period to period even though the expected value was falling. By period 10 the assets were trading at prices equal to the maximum possible yield and by period 11 prices were above the maximum possible yield. Such high prices could not have been due to optimism about fundamental values. In period 14 a violent market crash occurred as prices fall to levels near the expected value. The time series clearly demonstrates the properties of a bubble and a market crash.

A puzzle emerges. How can markets populated with rational agents have such properties? How can the models be changed to account for this phenomena?

The experimental literature and the theoretical literature contain some hints about possible solutions to all three paradoxes, the winner's curse, the centipede and asset market bubbles. 


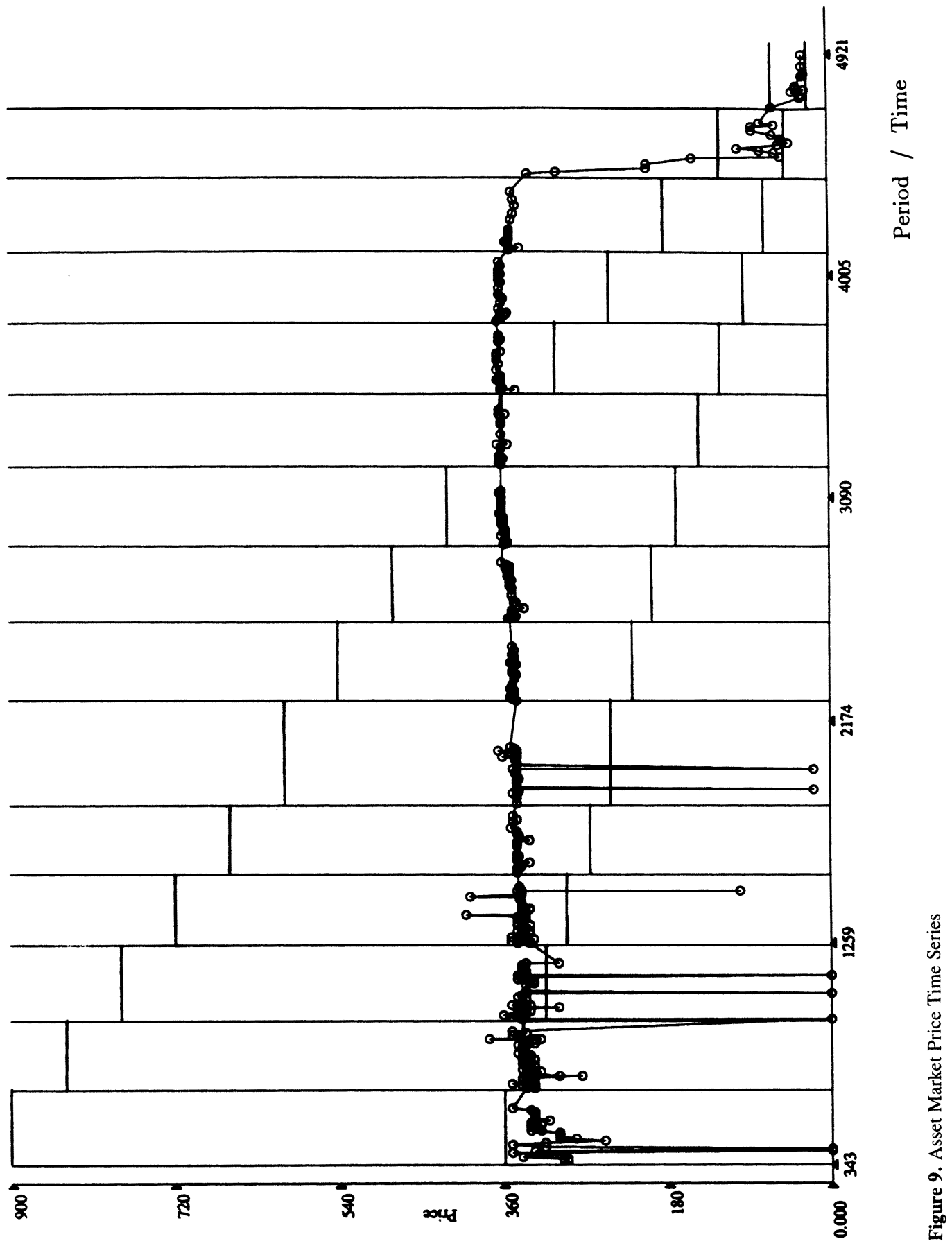


Rationality of agents might not be public information. Each agent might be rational but might also be unsure about the rationality of others. Perhaps the rationality of others is only learned by experience. Recall, in the centipede game, experience seemed to foster more Nash-like behavior. People seemed to learn that other people were prepared to defect. Similarly, the "bigger fool" beliefs could account for asset market bubbles. If an agent believes that he or she can sell the asset to someone else for the same price next period, then the dividend is obtained free. In the bubble experiments experience in asset markets makes the bubble "pop" sooner and after three or four such market experiences, the bubbles almost completely disappear. The fact that "bigger fools" do not exist may become public information with experience in the market. Even the early experiments by Forsythe, Palfrey and Plott exhibited properties that the authors called the "swing back hypothesis"-repeated experiences with final-period behavior become incorporated in the earlier decisions as agents deal repeatedly over the lifetimes of assets.

The suggested solution to the paradoxes is only speculation. However, if it is taken seriously it motivates a host of related questions. Do special market instruments exist (futures markets, options markets) that make public the rationality of individuals? If "irrationality" exists, exactly how might it be integrated into the models? The ideas suggested by Kreps, Milgrom, Roberts and Wilson [14] provide a start. The model developed by McKelvey and Palfrey to explain the centipede game depends heavily on such ideas. However, few people believe that theory should end with the "gang of four" paper and I should emphasize again that this proposed solution is not the only idea that exists.

\section{Step 6: Say's Law of Experimental Methods Takes Over}

The famous law of J. B. Say, that supply creates its own demand, seems applicable to the case of experimental research. The application of experimental methods generates research questions that can only be answered by a more intense use of experimental methods. The supply of experimental research creates a demand for even more experimental research. When Say's law of experimental methods takes over, the stage is set for an ever increasing tendency to use experiments. The stage becomes set for economics to slowly but surely become a laboratory experimental science.

The sections above illustrate how it has happened in one case. Experiments suggest that modern theory is on the right track (Step 4). Models based on principles of game theory clearly receive much support in the experimental literature. When applied to simple cases, such models are more accurate than any theory found in any branch of any other science that might be applied to those cases. However, paradoxes exist (Step 5). Phenomena exist that are clearly beyond the explanatory capacities of modern models. But the existence of such phenomena does not mean that theory should stop. Versions of the theory that might readily account for the phenomena by removing the central role of publicness of rationality already exist in the literature. Such theories are not particularly well developed and must be appended by special theories of information and learning. Considerably more experimental work will be necessary to determine if changes in the rationality postulates are the correct way to push theory and to narrow the options from the many different forms that such theory might take. This need for new experiments brings us to Step 6 . The supply of experimental research creates a demand for more experimental research.

I'm reminded of the joke about the man who was talking with his physician after having taken a series of tests the week before. The physician first tells the man the good news: "The test report said that you would die in twenty-four hours." Shocked and outraged, the man yells 
"How can you say that? How can that be good news? What could possibly be the bad news?" The physician looks at him sadly. "The bad news is," says the physician, "we got the test results yesterday."

To those who are not enthusiastic about the use of laboratory experimental methods, the prohibitionists so to speak, the good news is that the profession has tasted the devil's brew, the use of experimental methods, and likes it. "If that is the good news, what on earth could be the bad news?", the prohibitionists might ask. The bad news is that all six of the seductive steps to sin and intoxication have occurred in almost every subfield of economics. Those who have not been touched are being tempted. Say's law of experimental methods seems to be operating everywhere. The impact might not be noticeable yet but the process is operating.

Let me be clear about my answer to the question posed by the title of this paper. I do not believe that experimental methods will replace field research. Economies found in the wild can only be understood by studying them in the wild. Field research is absolutely critical to such an understanding. However, the theories and models used in field research necessarily incorporate many judgments about assumptions, parameters and behavioral principles. The simple cases that can be studied in the laboratory can provide the data against which the importance of such judgments can be assessed. Economics is one of the few sciences that is fortunate to have both the field and the laboratory with which to work. The thesis of this paper is that the laboratory methodology, which has historically been absent, will grow and become an important partner in a joint effort to isolate the principles which govern economic behavior.

\section{References}

108.

1. Chamberlin, Edward H., “An Experimental Imperfect Market." Journal of Political Economy 56 (1948): 95

2. Cox, James C., Bruce Roberson, and Vernon L. Smith. "Theory and Behavior of Single Object Auctions," in Research in Experimental Economics, edited by Vernon L. Smith. Greenwich, Conn.: JAI Press, 1982.

3. - Vernon L. Smith, and James M. Walker, "Theory and Individual Behavior of First Price Auctions." Journal of Risk and Uncertainty 1 (1988): 61-99.

4. Fiorina, Morris P. and Charles R. Plott, "Committee Decisions under Majority Rule." American Political Science Review, June 1978, 575-98.

5. Forsythe, R., T. R. Palfrey, and C. R. Plott, "Asset Valuation in an Experimental Market.” Econometrica, May $1982,537-67$

6. - , , and "Futures Markets and Informational Efficiency: A Laboratory Examination." Journal of Finance, September 1984, 955-81.

7. Fouraker, L. and S. Siegel. Bargaining and Group Decision Making: Experiments in Bilateral Monopoly. Reprint of 1960 Edition. Westport, Connecticut: Greenwood Press, 1977.

8. Friedman, Daniel, Glenn W. Harrison, and Jon W. Salman, "The Informational Efficiency of Experimental Asset Markets." Journal of Political Economy 92(1984): 349-408.

9. Friedman, James W. and Austin C. Hoggatt. An Experiment in Noncooperative Oligopoly. Research in Experimental Economics, Vol. 1, Supplement 1. Greenwich, Conn.: JAI Press, 1980.

10. Goodfellow, Jessica and Charles R. Plott, "An Experimental Examination of the Simultaneous Determination of Input Prices and Output Prices.” Southern Economic Journal, April 1990, 969-83.

11. Hoggatt, Austin C., "An Experimental Business Game.” Behavioral Science, July 1959, 192-203.

12. Hong, James T. and Charles R. Plott, "Rate Filing Policies for Inland Water Transportation: An Experimental Approach.” Bell Journal of Economics, Spring 1982, 1-19.

13. Kagel, John H. and Dan Levin, "The Winner's Curse and Public Information in Common Value Auctions." American Economic Review, December 1986, 894-920.

14. Kreps, D., Paul Milgrom, John Roberts, and Robert Wilson, "Rational Cooperation in the Finitely Repeated Prisoner's Dilemma." Journal of Economic Theory 23 (1982): 245-52.

15. Lind, Barry and Charles R. Plott, "The Winner's Curse: Experiments with Buyers and Sellers." American Economic Review 1991 (forthcoming). 
16. McKelvey, Richard D. and Thomas Palfrey. "An Experimental Study of the Centipede Game." Social Science Working Paper No. 732. Pasadena: California Institute of Technology, May 1990.

17. Plott, Charles R. "The Application of Laboratory Experimental Methods to Public Choice," in Collective Decision Making: Applications from Public Choice Theory, edited by C. S. Russell. Baltimore: Johns Hopkins Press for Resource for the Future, 1979, pp. 137-60.

18. - and Vernon L. Smith, "An Experimental Examination of Two Exchange Institutions." Review of Economic Studies February 1978, 133-53.

19. Sauermann, Heinz and Reinhard Selton, "Ein Oligopolexperiment." Zeitschrift für die Gesamte Staatswissenschaft 115 (1950): 427-71.

20. - "An Experiment in Oligopoly," in General Systems Yearbook of the Society of General Systems Research, Vol. 5, edited by Ludwig van Bertalanffy and Anatol Rappoport. Ann Arbor, Michigan: Society for General Systems Research, 1960, pp. 85-114.

21. Smith, Vernon L., "An Experimental Study of Competitive Market Behavior." Journal of Political Economy, April 1962, 111-37.

22. , Gerry L. Suchanek, and Arlington W. Williams, "Bubbles, Cracks and Endogenous Expectations in Experimental Spot Asset Markets.” Econometrica, September 1988, 1119-52. 